\title{
On Time-series Empirical Analysis of Tourism income and Economic Growth in Gansu China
}

\author{
Chaoji Yang ${ }^{a}$ and Haiying $\mathrm{Ma}^{\mathrm{b}^{*}}$ \\ School of Economics, Northwest University for Nationalities, Lanzhou (730124), P.R. China \\ a76580030@qq.com, ${ }^{\mathrm{b}}$ Ixmahaiying8888@163.com \\ "The corresponding author
}

Keywords: Tourism income; Economic growth; Empirical analysis; Gansu

\begin{abstract}
This paper conducts the causal analysis between TI (TI) and economic growth of Gansu province in China using time-series data from 1986-2010, and it is directed by the means of time-series estimations through ADF unit root test, co-integration tests, error-correction analysis and Granger causality test. The purpose of the paper is to empirically investigate the impact of economic growth on TI of Gansu in China. The results suggest that TI does not appear to Granger-cause economic growth, and economic growth also does not significantly affect TI, which means some studies have overestimated the positive effect of TI on economic growth, and underestimated the influence of economic growth on TI. The paper slao predicts the future development of tourism industry in Gansu.
\end{abstract}

\section{Introduction}

The tertiary industry in China developed slowly for a long term with a low proportion in the national economy before the reform and opening up, which was mainly influenced by three factors. Since 1978, China's tourism industry has entered a new historical due to the reform and opening. After 30 years of development, China has become the world tourist destination and established its distinctive image in the international arena, which has enhanced the mutual exchanges between China and the other countries, and expanded China's international influence. Clearly, tourism is a comprehensive economic industry. The clear recognition of the industrial nature has enhanced the awareness of tourism development of capital for the tourism industry and hence to impact positively the ecomonic development.

Gansu has rich in tourism resources. In 2009 the domestic tourist income reached 79.769 billion Yuan. the domestic demand from the residents in Gansu played an important role in the tourism development, and residents income had a major impact on the tourist income. However, the income from Gansu tourism and the related industries accounted for a very low percentage in GDP. Specifically, in 2007, 2008, and 2009, the total income of Gansu tourism accounted for respectively $18.97 \%, 19.46 \%$, and $21.55 \%$ of the provincial GDP. This indicates that there is a huge room for tourism development in Gansu. Therefore, the study on the influence of Gansu residents' income on its tourism development has important practical significance to maintaining a sustainable and rapid growth of Gansu tourism. From 1990 to 2009, GDP in Gansu has increased to 391.268 billion Yuan, with a 15-time growth, while tourism income has increased to 79.769 billion Yuan in 2009 from 0.09 billion yuan in 1990. It can be seen that GDP in Gansu growth was far slower than its tourism growth, indicating the considerable development prospects of Gansu tourism.

Many Scholars have consensus on the relationship between TI and economic growth. Some suggested that TI are positively related to economic growth [1-3], while others investigated that they are not the truth [4-5]. Some empirical studies show that both TI and economic growth are interdependent and could lead to two way causality [6]. From the above overview, we can find a blurred picture that the relationship between TI and economic growth is not clear, and one specific growth-enhancing effect of TI is ambiguous in their findings. Pavlopoulo[7] illustrate the importance of distinguishing between developed and developing countries. Other scholars have successfully 
addressed the endogeneity problem between TI and economic growth by means of instrumental variables techniques [3-8], Granger causality or VAR/VECM frameworks or the Arrelano-Bond generalized method of moments (GMM) approach. In china, an increasing number of studies also attempted to reveal the regional distribution of TI and economic growth. Hu [9] studied the great disparity between coastal and inland regions of TI and economic growth. Zhao [10] examined the uneven distribution among three regions. These studies confirmed the uneven distribution of TI and its positive power in China economy. Since "go west" policy, the growing TI into western region has become an important driving force of economic development. As the poorly-functioned province, Gansu is located in remote and inland of China with poor economic situation, there are few studies providing the causal relationships between TI and economic growth, especially in less-developed western region with large number of minorities' population. The objective in this paper is to examine the causal relationships between TI and economic growth of Gansu in China and to find its dynamical mechanism. The rest of this paper is organized as follows: section 2 presents data and methodology used in the paper. Section 3 examines empirical analysis and findings of causal relationships between TI and economic growth. The last section is the conclusion and implications.

\section{Date and Methodology}

In this paper, $T I$ is measured as the amount of foreign capital actually utilized and economic growth is measured as real GDP. The relationship between GDP and $T I$ of Gansu is examined on the basis of annual time series data for the period of 1986-2012. All the data used in this paper are obtained from China Statistics Yearbook 1987-2013. To achieve consistency, data reported in RMB are converted into USD dollars based on the current year average market exchange rates, which are produced by National Bureau of Statistics in China. For testing purpose, all time-series are expressed in real terms using a GDP deflator $(1978=100)$ and in natural logarithms.

In order to avoid spurious regression situation, all variables in a regression model must be stationary or co-integrated. However, several empirical studies concluded that many macroeconomic time series data are non-stationary. Therefore, in the first step, unit root tests are performed on the time series to investigate stationary on both $G D P$ and $T I$. According to Engle and Granger, if two variables are integrated of order one, 1 (1), and are co-integrated, then either uni-directional or bi-directional Granger causality must exist in the 1(0) variables once the two series satisfy the unit root properties, the paper carries out the co-integration test to examine whether there is a cause-and-effect relationship between GDP and $T I$ of Gansu in China. If the two series variables are found to be co-integrated, then we retrieve the error correction term from the co-integrating equation and test the direction of causation. If the two variables are not co-integrated, then we employ Granger's causality to test the direction of short-run causation.

\section{Empirical Analysis and Findings}

Unit Root Test. The augmented Dickey-Fuller test (ADF) (Dickey \& Fuller, 1979) is a test for a unit root in a time series sample. It's the augmented version of the Dickey-Fuller (DF) test for resolving the existence of autocorrelations phenomenon. It's also a larger and more complicated set of time series models, and it indicates the error term is not white noise. In order to check non-stationary in different level, we investigate the stationarity of the first difference of the series by testing for unit roots. It could be divided into three main versions which stating as followings:

No constant and no trend model:

$\Delta y_{t}=w y_{t-1}+\sum_{i=1}^{k} \beta_{i} \Delta y_{t-i}+\varepsilon_{t}$

Constant and no trend model:

$\Delta y_{t}=\alpha_{0}+\omega y_{t-1}+\sum_{i=1}^{k} \beta_{i} \Delta y_{t-i+1}+\varepsilon_{t}$

Constant and trend model: 


$$
\Delta y_{t}=\alpha_{0}+\alpha_{1} t+\omega y_{t-1}+\sum_{i=1}^{w} \beta_{i} \Delta y_{t-i+1}+\varepsilon_{t}
$$

Where $\Delta$ means first difference, $y_{t}$ is predictor variable, $\alpha$ is the intercept. $\omega$ stands for auto-regression term, $\alpha_{1} t$ is the time trend term and $\sum_{i=1}^{w} \beta_{i} \Delta y_{t-i+1}$ refers to lag term of dependent variables, $\varepsilon_{t}$ represents the error term.

The hypothesis of unit root is: $\mathrm{H}_{0}: \mathrm{w}=0$ and $\mathrm{H}_{1}: \mathrm{w} \neq 0$

If the null hypothesis $\left(\mathrm{H}_{0}\right)$ is rejected, it concludes to reject the variables existing the unit root. Thus, the predictor variable will be the stationary time series.

Table 1 is the results of the ADF test, and it show that the null hypothesis of a unit root is (a) accepted for the level series of GDP in three models; (b) rejected for the level series of $T I$ in the model (2), and (c) rejected for all the first differenced series (except GDP in model 1). Therefore the null hypothesis of non-stationary could not be rejected, and both of the series are stationary. We can say that both times series are integrated of order $1,1(1)$.

Table 1 results of ADF unit root test

\begin{tabular}{llll}
\hline Variables & $\begin{array}{l}\text { Model (1) } \\
\text { No constant \& No trend }\end{array}$ & $\begin{array}{c}\text { Model (2) } \\
\text { Constant \& No trend }\end{array}$ & $\begin{array}{c}\text { Model (3) } \\
\text { Constant \& No trend }\end{array}$ \\
\hline $\begin{array}{lll}\text { 1. ADF test for unit root on the level series } \\
G D P\end{array}$ & 6.6623 & $-3.1441 *$ & 0.5676 \\
\hline$T I$ & 0.4768 & $-4.2776 *$ & -1.5632 \\
\hline 2. ADF test for unit root on the first difference series & $-5.6712 *$ \\
\hline$G D P$ & 0.8677 & $-4.8789 *$ & $-5.6389 *$ \\
\hline
\end{tabular}

Notes: * denotes significance at the $1 \%$ level

Co-integration Test. Since all the data series are integrated processes of order 1 (1), the co-integration test will be performed to examine the long run or equilibrium relationship between the variables of GDP and FDI. The co-integration test applies the best method of co-integration log likehood ratio (LR) brought forward by Johanson. The results of the Johanson co-integration is summarised in Table 2, which provide evidence to reject the null of zero co-integrating vectors in favour of one co integrating vector at the $1 \%$ level of significance. The test statistics suggests that there exists a long equilibrium relationship between $G D P$ and $T I$ of Gansu.

Table 2 Results of Johansen Co-integration Test

\begin{tabular}{c|c|c|c|c|c}
\hline \multirow{2}{*}{ H0:rank=i } & Eigenvalue & $\begin{array}{c}\text { Likehood } \\
\text { Ratio Test }\end{array}$ & $\begin{array}{c}5 \% \text { Critical } \\
\text { Value }\end{array}$ & $\begin{array}{c}1 \% \text { Critical } \\
\text { Value }\end{array}$ & No. of CE(s) \\
Rank=0 & 0.9012 & 14.165 & 14,6545 & 17.35 & None $*$ \\
Rank $\leq 1$ & 0.0843 & 1.6451 & 3.68 & 6.83 & At most 1 \\
\hline
\end{tabular}

Notes: *denotes rejection of the null hypothesis at the $1 \%$ level.

The Error Correction Model. Engle and Granger show that if non-stationary variables are co-integrated, then a vector autoregression (VAR) in the first differences is misspecified. Since a co-integration relationship is found between $G D P$ and $T I$, an error correction model (ECM) is used to test for intermporal causality between these variables. Table 3 presents the results of the error correction models. 
Table 3 The results of the Estimation of Error Correction Model

\begin{tabular}{ccc}
\hline Variables & $\Delta G D P_{t}$ & $\Delta T I$ \\
\hline$\Delta G D P_{t-1}$ & $/$ & $0.6959 *$ \\
$(2.6987)$
\end{tabular}

Notes: figures in parentheses are t statistics; * denotes significance at the $1 \%$ level

As shown in the table 3, the estimation coefficient of the interpretive variable $\Delta_{t-1}$ in the ${ }_{\triangle} G D P$ equation indicates that $T I$ reduces $G D P$, however, the ${ }^{p}$ value of null hypothesis of the Wald test statistics is -0.3436 , which shows that the estimation value is beyond statistical significance. The next step of the test is to find out whether the error correction coefficient or co-integration coefficient is zero. Though the error correction coefficient of the $\triangle G D P$ equation is -0.0112 , the ${ }^{p}$ value of the null hypothesis of the Wald test statistic indicates that the significance in statistic terms is null. As a result, the assumption that $T I$ impels $G D P$ is false.

The same method is applicable to testing whether the economic development of western region attract $T I$. First of all, the estimation coefficient of $\Delta T I$ affected by $\Delta G D P_{t-1}$ tells that the economic development of western region stimulates $T I$, the ${ }^{p}$ value of the null hypothesis of Wald test statistics indicates that the assumption in statistics terms is significant. The ${ }^{p}$ value of the null hypothesis with further application of the Wald test and the significance in statistics terms in not null. The test results support the hypothesis that the economic development attracts $T I$.

The Granger Causality Test. If the variables are non-stationary and co integrated, the adequate method to examine the causal relations is the Vector Error Correction Model (VECM) [14]; otherwise a VAR model is used in the case of no co integration found among the variables.

The results of the GC test are shown in Table 4. They indicate that a zero hypothesis that economic development growth does not influence $T I$ can be rejected which implies adoption of the opposite hypothesis, i.e., that economic growth affects $T I$. Similarly, a non-rejection of the zero hypotheses that TI does not influence economic growth implies that we cannot adopt the opposite hypothesis that $T I$ affects economic growth. In short, the assumption that economic growth attracts $T I$ is confirmed, reverse causality, i.e. that $T I$ affects economic growth, is rejected.

Table 4 Granger Causality Test

\begin{tabular}{cccc}
\hline Null hypothesis & Observations & F-Statistics & Probability \\
\hline$T I$ does not cause $G D P$ & 23 & & \\
\hline$G D P$ does not cause $T I$ & & 2.20453 & 0.9421 \\
\hline
\end{tabular}

Notes: $*$ denotes significance at the $5 \%$ level

Findings. Since economic growth in western region affects $T I$ in the light of above analysis, we can establish the following:

$L N T I=\alpha+\beta L N G D P$

Above Equation is estimated by pooled ordinary least square (Pooled OLS), and the results are shown by E-view6.0 as following:

$L N T I=2.0341+0.682 L N G D P \quad R^{2}=0.936 \quad F=311.120 \quad D W=1.126$

It indicates that economic growth has played a positive role on $T I$, that is, GDP increase $1 \%, T I$ will increase $0.68 \%$.

\section{Conclusions}


This paper has analyses of the linkage between $G D P$ and $T I$ of Gansu province in China, by conducting time-series data through ADF unit root tests, co-integration tests, error-correction analysis and Granger causality test. The results show that TI does not appear to Granger-cause economic growth and economic growth also does not significantly affect $T I$. Based on the finding in this paper, we may draw some conclusions that host government should not only encourage $T I$ inflows, but also should take measures to improve the quality of utilizing $T I$ so as to achieve the goal of promoting economic growth as far as possible. Based on the close relationship between Gansu GDP and tourism income, Gansu Province should take full advantage of its abundant tourism resources and grasp the opportunity of implementing the Western Development Policy, so as to bring unprecedented advantageous external conditions for Gansu tourism. Taking hold of this historic moment, we should create an internal environment that is suitable for the development of tourism industry, and employ modern marketing methods and technologies to facilitate supernormal development of Gansu tourism industry, finally pushing forward Gansu GDP growth.

\section{References}

[1] Ballaguer, J. \& Cantavella-Jorda, M.. Tourism as a long-run economic growth factor: the Spanish case. Applied Economics, 34(2002)877-884.

[2] Bhagwati, J. and Srinivasan, T, Trade policy and development, in R. Dornbush and J. Frenkel, International Economic Policy: Theory and evidence, Johns Hopkins University press, Baltimore, pp. 12(1979)1-35

[3] Dritsakis, N., Tourism as long-run economic growth factors: an empirical investigation for Greece using causality analysis. Tourism Economics. 10 (2004) 305-316.

[4] Harding, D. \& Pagan, A.,. A comparison of two business cycle dating methods, Journal of Economics \& Control, (9(2003)1681-1690.

[5] Hou Guisheng, Thoughts about Development Strategy of Gansu Tourism, Journal of Gansu Nationalities University, 2000.

[6] Narayan, P. K., Economic Impact of tourism on Fiji's economy: empirical evidence from the computable general equilibrium model. Tourism Economics, 4 (2004) 419-433.

[7] Pavlopoulos, P, The Size and the Dynamic of the Tourism Sector. Research Institute for Tourism (ITEP), Athens. 1999

[8] Sugiyarto G., Blake A., Sinclair T, Tourism and globalization: economic impact in Indonesia, Annals of Tourism Research, 30 (2003) 683-702.

[9] Xiaohua Hu, Xiao Lin, A Study of the Relationship between Electricity Consumption and GDP Growth in Hainan International Tourism Island of China, Research in World Economy,4 (2013)109-112

[10]Zhao Lixian, Gansu Tourism Resource and Tourism Economy, Gansu Ethnic Studies, Journal of Southwest Agricultural University (Social Science Edition), 2010.

[11] Gao Su-ying, Tian Li-fa, Zhou Jian, Zhang Yan-li, Tourism foreign exchange income and economic growth in China: A panel cointegration approach, International Conference on Management Science and Engineering , 9(2009) 950-955. 